\title{
A TEM STUDY OF THE EFFECT OF PLATINUM GROUP METALS IN ADVANCED SINGLE CRYSTAL NICKEL-BASE SUPERALLOYS
}

\author{
A. P. Ofori ${ }^{1}$, C. J. Humphreys ${ }^{1}$, S. Tin ${ }^{1}$, C. N. Jones ${ }^{2}$ \\ ${ }^{1}$ Materials Science Department, University of Cambridge, Pembroke Street, Cambridge, CB2 3QZ, UK \\ ${ }^{2}$ Rolls Royce plc, PO Box 31, Derby, DE24 8BJ, UK
}

Keywords: PGMs, EDS, ALCHEMI, partitioning.

\begin{abstract}
Several effects of platinum group metal (PGM) additions to Nibase alloys were investigated using a transmission electron microscope (TEM). An experimental Re-containing alloy, Cantab17 (C17), was designed to reflect current third generation single crystal superalloys. Various levels of Ru, Rh, Ir, Pd and Pt were then systematically added to investigate the effects of these alloying elements. In addition to this, ternary Ni-19at\%Al3at $\%$ PGM alloys were investigated. $\gamma / \gamma$ ' phase partitioning ratios determined through TEM-EDS showed that for the C17-based alloys, $\mathrm{Ru}$ was the only PGM to partition to $\gamma$, while elevated levels of Rh, Ir, Pd and Pt were observed to reside within the $\gamma$ ' phase. Atomic site location (Al site or Ni site) of the PGMs in $\mathrm{Ni}_{3} \mathrm{Al}$ were found through ALCHEMI (atomic site location by channelling enhanced microanalysis) on the ternary Ni-Al-PGM alloys. Results showed that $\mathrm{Ru}$ preferentially partitions to $\mathrm{Al}$ sites with the other PGMs invariably showing some preference for $\mathrm{Ni}$ sites. Finally, a mechanism is proposed to explain the correlation between $\gamma / \gamma^{\prime}$ phase partitioning and $\gamma^{\prime}$ atomic site location of the PGMs in advanced superalloys.
\end{abstract}

\section{Introduction}

Throughout their history Ni-base superalloys have formed the materials leading edge for turbine blades in aeroengines. They are characterised by their excellent mechanical properties and oxidation resistance at high homologous temperatures. Lower densities and improved mechanical performance have been the two driving forces pushing alloy development [1]. Advanced single crystals are used in blades that experience the highest metal temperatures in the aeroengine turbine, and these materials are the product of long-term development in both composition and processing technology. Although the upper temperature at which these alloys are used is approaching their theoretical limit, currently operating at a maximum in excess of $90 \%$ of their melting point, there is some interest as to whether the addition of PGMs may further extend the temperature capability of these unique alloys.

Previous investigations that have been carried out on PGM containing superalloys have tended to either focus on mechanical properties [2-4] or oxidation/corrosion resistance [5-9]. Only a limited number of studies have been carried out examining the fundamental effects of the PGMs in advanced single crystal alloys containing up to $6 \mathrm{wt} \% \operatorname{Re}[10,11]$. Given the potential commercial benefits that may be realised when certain PGMs are incorporated in such alloys, there is a clear need to further explore the underlying manner in which these metals affect superalloy microstructure.

\section{Experimental Procedure}

The main base alloy used for this study was designated (C17). This alloy is an experimental alloy and was designed around existing third generation single crystal alloys. It should be noted that $\mathrm{Cr}$ is absent from the composition. To this alloy was added 1, 3 and 5 at $\%$ of $\mathrm{Ru}, \mathrm{Rh}, \mathrm{Ir}, \mathrm{Pd}, \mathrm{Pt}$, individually. In addition to this a binary $\mathrm{Ni}-\mathrm{Al}$ alloy was prepared which had a similar volume fraction of $\gamma^{\prime}$ when compared to C17. By making additions of 3 at $\%$ of each PGM, a series of $\gamma-\gamma^{\prime}$ Ni-Al-PGM ternary alloys were also fabricated.

The C17-based alloys were prepared by vacuum arc melting appropriate quantities of high purity PGM sponge to VIM barstock of $\mathrm{C} 17$. The ternary Ni-Al-PGM alloys were also prepared using arc-melting of high purity elemental additions. Chemical composition of all the alloys were verified using SEMEDS. The nominal compositions of the alloys are given in Table Ii as is the naming convention, which shall be used hereafter. The alloys were given a standard heat treatment consisting of $8 \mathrm{~h}$ at $1365^{\circ} \mathrm{C}$ to dissolve eutectic $\gamma$; followed by primary ageing at $1150^{\circ} \mathrm{C}$ to refine the $\gamma$ ' precipitates to approximately $0.5 \mu \mathrm{m}$. The ternary alloys were subjected to the same thermal cycle, however the precipitate size tended to be quite coarse (up to $2 \mu \mathrm{m}$ ) following the primary age.

Table Ii: Nominal compositions (at $\%$ ) for the alloys used.

\begin{tabular}{|c|c|c|c|c|c|c|c|}
\hline Alloy & Ni & Al & Co & W & Ta & Re & PGM \\
\hline C17 & 65.7 & 14.1 & 12.9 & 3.2 & 2.1 & 2.0 & - \\
\hline C17+1PGM & 65.0 & 14.0 & 12.8 & 3.2 & 2.1 & 2.0 & 1.0 \\
\hline C17+3PGM & 63.7 & 13.7 & 12.5 & 3.1 & 2.0 & 1.9 & 3.0 \\
\hline C17+5PGM & 62.4 & 13.4 & 12.3 & 3.0 & 2.0 & 1.9 & 5.0 \\
\hline Ni-19.5Al & 80.5 & 19.5 & - & - & - & - & - \\
\hline Ni-19Al-3PGM & 78.1 & 18.9 & - & - & - & - & 3.0 \\
\hline
\end{tabular}

The heat treated specimens were examined using X-ray diffraction (XRD) and a variety of optical and electron microscopy techniques, however, the focus of this paper are the results referring to the data collected using a TEM. A Philips FEGTEM CM300 was used. For this microscope, the electron source was provided by a field emission gun (FEG) Schottky emitter. EDS was performed through an EDAX ultra-thin window (UTW) Xray detector. The energy resolution of the detector was quoted as approximately $133 \mathrm{eV}$. An EMISPEC data acquisition system running ES Vision software recorded the X-ray signal.

TEM specimens were prepared by mechanically grinding thin discs of sample material followed by electrolytic thinning. A twinjet polisher along with a solution of $10 \mathrm{vol} \%$ perchloric acid in ethanol at approximately $-5^{\circ} \mathrm{C}$ was used for this latter stage. 
Table Iii: Nominal compositions (mass \%) for the C17-based alloys used.

\begin{tabular}{|c|c|c|c|c|c|c|c|}
\hline Alloy & Ni & Co & W & Al & Ta & Re & PGM \\
\hline $\mathrm{C} 17$ & bal. & 12.0 & 9.3 & 6.0 & 6.0 & 6.0 & - \\
\hline $\mathrm{C} 17+1 \mathrm{Ru}$ & bal. & 11.8 & 9.2 & 5.9 & 5.9 & 5.9 & 1.6 \\
\hline $\mathrm{C} 17+3 \mathrm{Ru}$ & bal. & 11.4 & 8.9 & 5.7 & 5.7 & 5.7 & 4.7 \\
\hline $\mathrm{C} 17+5 \mathrm{Ru}$ & bal. & 11.1 & 8.6 & 5.5 & 5.5 & 5.5 & 7.7 \\
\hline $\mathrm{C} 17+1 \mathrm{Rh}$ & bal. & 11.8 & 9.2 & 5.9 & 5.9 & 5.9 & 1.6 \\
\hline $\mathrm{C} 17+3 \mathrm{Rh}$ & bal. & 11.4 & 8.9 & 5.7 & 5.7 & 5.7 & 4.8 \\
\hline $\mathrm{C} 17+5 \mathrm{Rh}$ & bal. & 11.1 & 8.6 & 5.5 & 5.5 & 5.5 & 7.9 \\
\hline $\mathrm{C} 17+1 \mathrm{Pd}$ & bal. & 11.8 & 9.1 & 5.9 & 5.9 & 5.9 & 1.7 \\
\hline $\mathrm{C} 17+3 \mathrm{Pd}$ & bal. & 11.4 & 8.8 & 5.7 & 5.7 & 5.7 & 4.9 \\
\hline $\mathrm{C} 17+5 \mathrm{Pd}$ & bal. & 11.0 & 8.5 & 5.5 & 5.5 & 5.5 & 8.1 \\
\hline $\mathrm{C} 17+1 \mathrm{Ir}$ & bal. & 11.6 & 9.0 & 5.8 & 5.8 & 5.8 & 3.0 \\
\hline $\mathrm{C} 17+3 \mathrm{Ir}$ & bal. & 11.0 & 8.5 & 5.5 & 5.5 & 5.5 & 8.6 \\
\hline $\mathrm{C} 17+5 \mathrm{Ir}$ & bal. & 10.4 & 8.0 & 5.2 & 5.2 & 5.2 & 13.8 \\
\hline $\mathrm{C} 17+1 \mathrm{Pt}$ & bal. & 11.6 & 9.0 & 5.8 & 5.8 & 5.8 & 3.0 \\
\hline $\mathrm{C} 17+3 \mathrm{Pt}$ & bal. & 11.0 & 8.5 & 5.5 & 5.5 & 5.5 & 8.7 \\
\hline $\mathrm{C} 17+5 \mathrm{Pt}$ & bal. & 10.3 & 8.0 & 5.2 & 5.2 & 5.2 & 13.9 \\
\hline & \multicolumn{7}{|c}{}
\end{tabular}

To perform statistical ALCHEMI, the TEM was used in rocking beam mode. ALCHEMI exploits the principle that a transmitted electron beam will cause excitation of an atom within a sample that is specific to the local environment in which the atom sits. By pivoting the electron beam about the sample, a rocking beam Xray map can be collected for any element that is present. Quantification of similarities between host (in this case Ni and $\mathrm{Al}$ ) site maps and dopant (in this case the PGMs) site maps gives a measure of relative site partitioning.

The X-ray spectra were collected as a function of position, as a $200 \mathrm{kV}, 50 \mathrm{~nm}$ electron beam was scanned about a $95 \times 75 \mathrm{mrad}$ surface centred on a low-index major zone axis of a $\gamma$ ' precipitate. The way in which similar atomic sites line up when $\mathrm{Ni}_{3} \mathrm{Al}$ is viewed along the $\langle 100\rangle$ and $\langle 111\rangle$ zone axes made these orientations the most suitable for ALCHEMI. The spectra were recorded over a $80 \times 60$ step array, with an acquisition time of $1.5 \mathrm{~s}$ per spectrum and a count rate of about 10,000 counts per second. Once acquisition was completed, the 4800 spectra were processed to give background-subtracted elemental maps for $\mathrm{Ni}, \mathrm{Al}$ and any other alloying additions. Statistical ALCHEMI relies on the premise that the partitioning of a doping species is given by the extent of superposition required to form the dopant map from the host site maps. Application of $\chi^{2}$-minimisation to the data from the series of maps gave atomic site partitioning values as well as a measure of confidence in the fit of the model.

\section{$\underline{\gamma / \gamma}$ ' Partitioning Ratios}

\section{Results}

The results from TEM-EDS are shown graphically in Figure 1. The partitioning coefficient is defined as $k_{i}=C_{i}^{\gamma} / C_{i}^{\gamma^{\prime}}$, where $i$ represents each of the constituent elements. Since $C_{i}^{\gamma}$ and $C_{i}^{\gamma^{\prime}}$ correspond to the levels of element $i$ in the $\gamma$ and $\gamma^{\prime}$ phases, respectively, partition coefficients greater or less than unity indicate preferential partitioning to either the $\gamma^{\prime}$ or $\gamma$ phase.

Representative microstructures from the as-cast and heat treated condition for selected C17+PGM alloys are shown in Figures 2 and 3. After solutioning and primary ageing heat treatment, the majority of the alloys exhibited microstructures consisting of coherent cuboidal $\gamma$ ' precipitates contained within a continuous $\gamma$ matrix. With alloying levels above $3 \mathrm{at} \% \mathrm{Rh}$ and $\mathrm{Pd}$, the twophase $\gamma / \gamma$ ' solubility limit in $\mathrm{C} 17$ was exceeded and thus a third phase formed upon casting (see Figure 2). XRD showed this to be $\beta$ (based on $\mathrm{B} 2(\mathrm{Rh}, \mathrm{Ni}) \mathrm{Al}$ ) in the case of Rh bearing alloys and $\rho$ (based on $\left.\mathrm{C} 23(\mathrm{Pd}, \mathrm{Ni})_{2} \mathrm{Al}\right)$ in the case of $\mathrm{Pd}$-containing alloys. The presence of these phases made it impossible to attain a homogeneous $\gamma+\gamma$ ' microstructure through heat treatment (see Figure 3). Consequently, the $\gamma / \gamma^{\prime}$ partitioning ratios for these alloys should be treated with caution. The presence of $\mathrm{Pd}$ and $\mathrm{Rh}-$ rich phases was likely to have had a leeching effect on the composition, strongly decreasing the amount of $\mathrm{Rh}, \mathrm{Pd}, \mathrm{Ni}$ and $\mathrm{Al}$ available for $\gamma$ and $\gamma$ ' formation. In some cases it was found that the volume fraction of the alloys changed as the PGMs were added, the nature of which has been discussed elsewhere [12]. Summarising, it was observed that $\gamma^{\prime}$ content decreased with rising $\mathrm{Ru}$ concentration, and increased when Ir was added.

In general, micro-compositional variations were observed throughout the microstructure for all of the specimens. Taking averages of the partitioning ratios was therefore an important part of attaining representative accuracy throughout the sampling areas. The individual ratios shown in Figure 1 were calculated using five matrix-precipitate combinations oriented close to $<100>$. A single partitioning ratio was calculated based on one matrix-precipitate combination and the final ratio for any element was taken as the logarithmic mean of the five partitioning ratios. The statistical fluctuation associated with the measured data were all within an average deviation of \pm 0.2 of the values plotted in Figure 1.

It is interesting to compare the effect of PGM partitioning with changing concentration in the $\mathrm{C} 17+\mathrm{PGM}$ series of alloys (Figure 1a). $\mathrm{Ru}$ is the only PGM to preferentially partition to $\gamma$ in the C17based alloys, yet in accordance with Ir and Pt the potency of phase partitioning decreases with increasing concentration. This is especially true for $\mathrm{Pt}$, where the partitioning ratio increases dramatically from 0.39 at 1 at $\%$ to 0.61 at 5 at $\%$. Pd and Rh behave differently as both result in an increasing tendency to partition to $\gamma$ ' with increasing concentration, the former more so that the latter. With all the PGMs, the variation of the partitioning ratio with atomic concentration appears linear on the logarithmic plot, implying an exponential relationship.

Also of interest is the effect of PGM content on the elements contained in the $\mathrm{C} 17$. Broadly, as $\mathrm{Ru}$ is added to $\mathrm{C} 17$ a marked decrease occurs in the partitioning tendency of the elements. Ni which preferentially partitions to $\gamma$ in $\mathrm{C} 17$ switches to $\gamma^{\prime}$ in the $\mathrm{Ru}$-containing alloys, albeit a very slight effect.

In many respects $\mathrm{Ir}$ acted in a similar way to $\mathrm{Ru}$, but with less potency. Attenuated partitioning of the $\mathrm{C} 17$ elements was observable at 1 at $\% \mathrm{Ir}$, with the exception of Ta. The addition of 3 and $5 \mathrm{at} \%$ caused little change above that seen in $\mathrm{C} 17+1 \mathrm{Ir}$, and the partitioning ratios remain fairly constant with increasing Ir concentration. The degree of Ta partitioning to the $\gamma^{\prime}$ phase, on the other hand, was observed to increase with increasing Ir content.

At the 1at\% level in the C17-based alloys, Pt acts in a near identical manner to Ir showing attenuated partitioning for most elements in $\mathrm{C} 17$, but in this case $\mathrm{W}$ was found to be insensitive to 

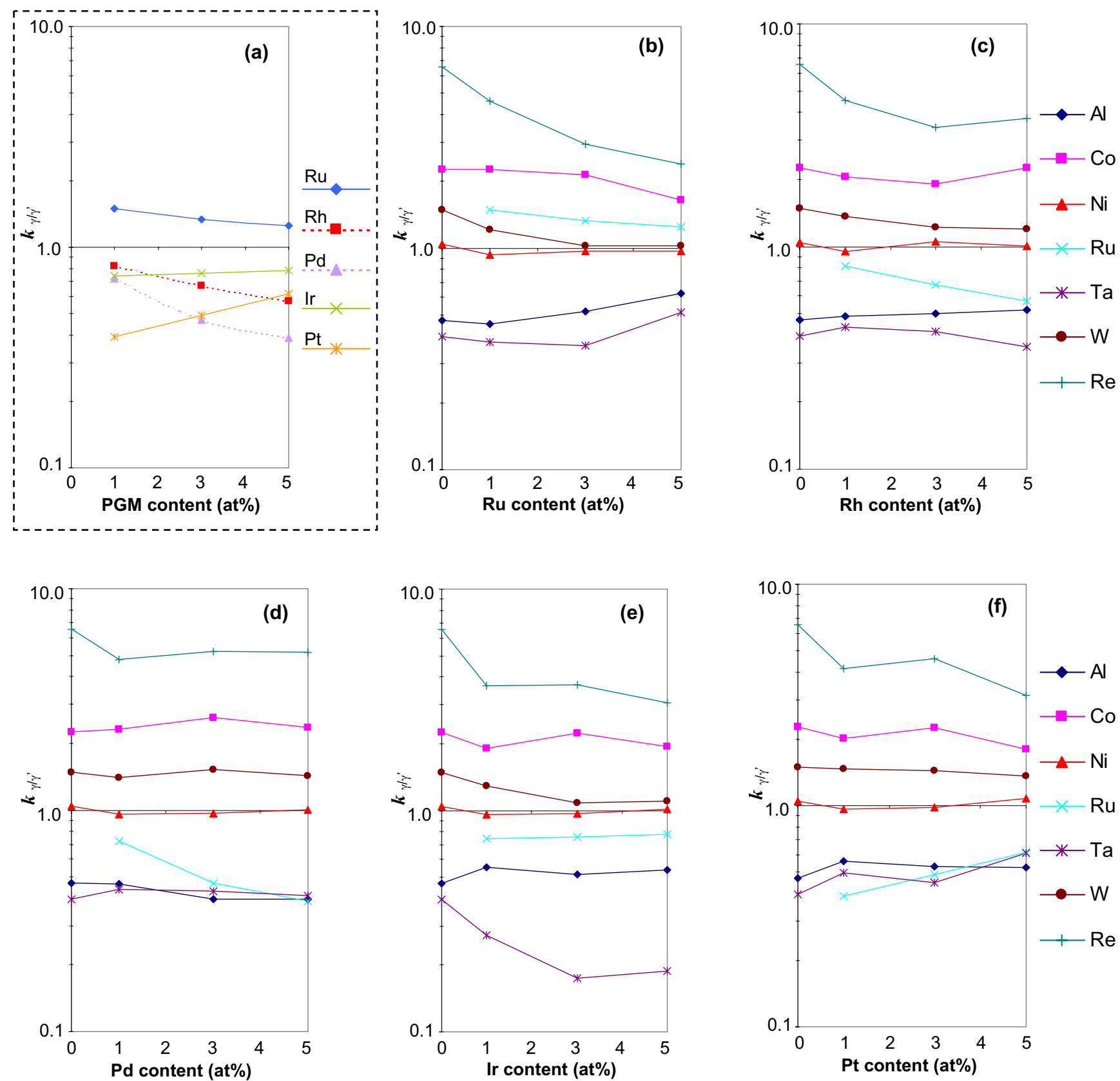

Figure 1: $\gamma-\gamma^{\prime}$ partitioning ratios for the series of PGM doped alloys: a) exclusively comparing PGM behaviour; and (b) to (f) assessing the effect of PGM addition on the constituent elements of the alloy.

any $\mathrm{Pt}$ concentration. Also above $1 \mathrm{at} \%$ little variation of the elemental ratios was observed with Pt content.

The addition of $\mathrm{Rh}$ up to $3 \mathrm{at} \%$ decreases the degree of partitioning for the other constituent elements present in $\mathrm{C} 17$. With the addition of $5 \mathrm{at} \% \mathrm{Rh}$ the partitioning ratios either remain the same as that observed at $3 \mathrm{at} \%$ or revert back to the values seen at $1 \mathrm{at} \%$. The partitioning ratios between $3 \mathrm{Rh}$ and $5 \mathrm{Rh}$ were strongly affected by the presence of the third phase within the microstructure. Consistent with the depletion of Rh from the $\gamma+\gamma$ ' matrix due to precipitation of $\beta$, detailed analysis of the composition data shows that there is little variation in the average $\mathrm{Rh}$ content in $\gamma / \gamma$ ' between $\mathrm{C} 17+3 \mathrm{Rh}$ and $\mathrm{C} 17+5 \mathrm{Rh}$.
Microstructural differences between the ternary Ni-19Al-3Rh alloy and the $\mathrm{C} 17+3 \mathrm{Rh}$ alloy (namely greater $\beta$ precipitation in the latter) were believed to be a manifestation of differences in $\gamma / \gamma^{\prime}$ partitioning behaviour: the preference for $\mathrm{Rh}$ to reside in $\gamma$ ' was more intense in the complex, multi-component alloy. In the Ni-19Al-3Rh alloy $k_{\gamma / \gamma^{\prime}, R h}=0.9$, while $k_{\gamma / \gamma^{\prime}, R h}=0.7$ for $\mathrm{C} 17+3 R \mathrm{R}$.

Although PGM-induced changes in the $\gamma / \gamma^{\prime}$ partitioning of constituent elements were measured in the Pd-containing alloys, the extent to which this occurred was smaller than any of the other PGMs. C17+1Pd showed the biggest effect, but even then only two of the elements ( $\mathrm{Re}$ and $\mathrm{Ta}$, which are the strongest partitioning elements) showed significant changes. Compared to 

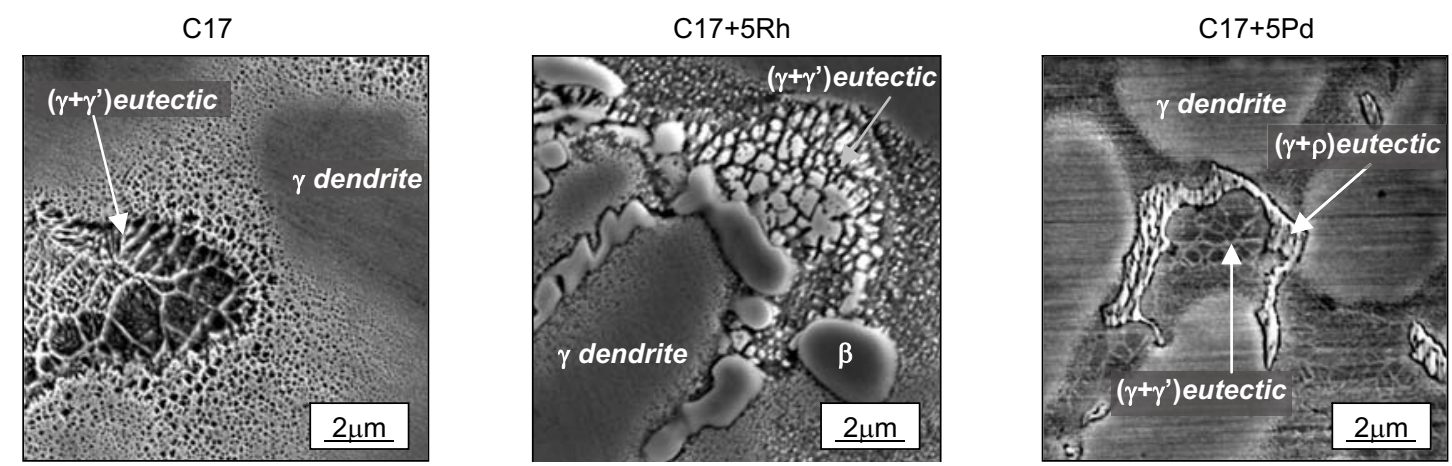

Figure 2: As-cast microstructure (SEM, secondary electron images) of $\mathrm{C} 17, \mathrm{C} 17+5 \mathrm{Rh}$ and $\mathrm{C} 17+5 \mathrm{Pd}$. On casting most of the $\mathrm{C} 17$ based alloys showed a similar microstructure to $\mathrm{C} 17$. However, $\mathrm{C} 17+3 \mathrm{Rh}, \mathrm{C} 17+5 \mathrm{Rh}, \mathrm{C} 17+3 \mathrm{Pd}$ and $\mathrm{C} 17+5 \mathrm{Pd}$ showed evidence of other phases in addition to the conventional $\gamma$ dendrites and $\gamma+\gamma$ ' eutectic. All magnifications are identical.

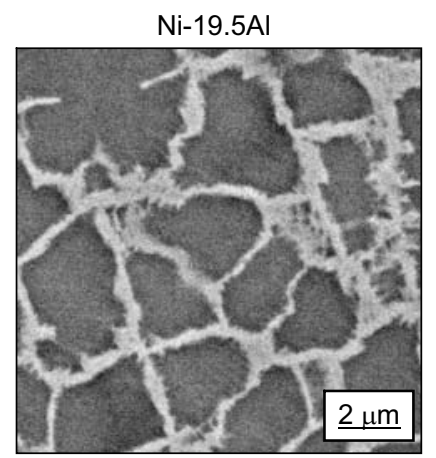

$\mathrm{Ni}-19 \mathrm{Al}-3 \mathrm{Ru}$
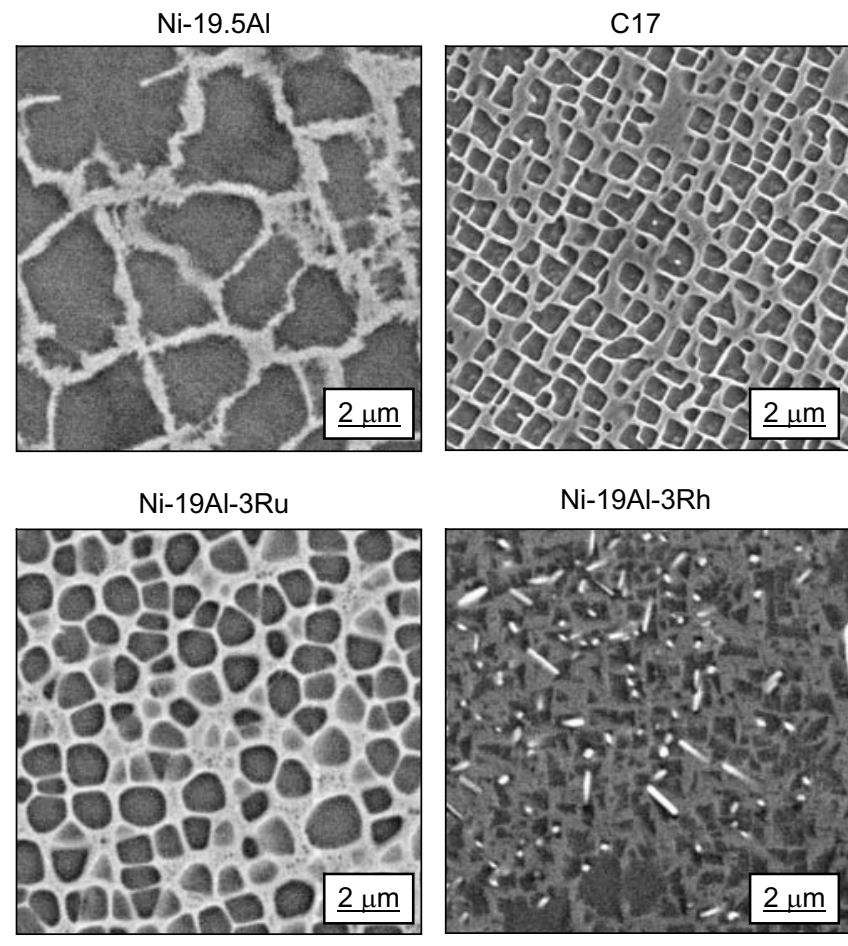

Ni-19Al-3Rh

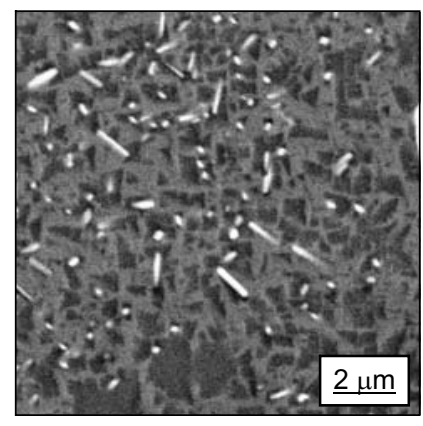

Figure 3: Solutioned + primary aged microstructures (SEM, backscatter electron images). The heat treatment used produced $\sim 0.5 \mu \mathrm{m} \gamma$ ' precipitates in C17-based alloys, however the precipitates tended to be significantly larger in the ternary alloys. The PGMs appeared to have a strong effect on precipitate morphology as well. Ni-19Al-3Rh was different to the other ternary alloys since it precipitated a third phase during ageing, identified as $\beta$ (with the $\mathrm{B} 2$ structure).

the Rh-bearing alloys, partitioning of Pd in the simple ternary Ni19Al-3Pd alloy was close to that of the complex multicomponent C17+3Pd alloy.

Application of Statistical ALCHEMI to $\gamma$ ' Precipitates in Ni-Al-X $\underline{\text { Alloys }}$

To begin with, an attempt was made to determine the extent of partitioning of all the elements as found in $\gamma$ ' belonging to the $\mathrm{C} 17$ based alloys. However, the $\mathrm{Ni}$ and $\mathrm{Al}$ host site maps were too similar to one another in these multicomponent alloys.
Computational simulations revealed that the degree of alloying in $\gamma$ ' severely limited the application of ALCHEMI. In particular, atomic delocalisation and X-ray absorption were shown to strongly attenuate the differential responses on which ALCHEMI hinges [12].

Simulations also indicated that simplified ternary $\gamma-\gamma^{\prime}$ alloys with fewer elemental additions would be more suitable for analysis. This was confirmed through a rocking beam scan on a binary Ni$19.5 \mathrm{Al}$ alloy that showed excellent site discrimination between $\mathrm{Ni}$ and $\mathrm{Al}$ (Figure 4a). Calculations also showed that there was only a slight improvement in the channelling effects offered by the low temperature scans on simple alloys. Consequently room temperature scans were used as standard for the ternary alloys. A scan was performed on Ni-19Al-3Ta to check the accuracy of the technique. The advantage of using Ta (an Al-site partitioning element) was that it tested the ability of the technique to resolve data from the "weaker" sublattice site. In keeping with the findings of other researchers, an approximate $\gamma$ ' concentration of $4 \mathrm{at} \% \mathrm{Ta}$ was found to exhibit an extremely high preference $\left(97 \pm 2 \%\right.$ ) for the $\mathrm{Al}$ sites in $\mathrm{Ni}_{3} \mathrm{Al}$ (see Table II). It should be noted however that the quantitative accuracy of the data may be questioned given the close proximity in X-ray energy between the $\mathrm{Ta}_{\mathrm{M} \alpha}$ line $(1.71 \mathrm{keV})$ and the $\mathrm{Al}_{\mathrm{K} \alpha}$ line $(1.49 \mathrm{keV})$. Similar experiments were performed on the Ternary Ni-19Al-3PGM alloys. An example of a series of X-ray channelling maps for $\gamma^{\prime}$ in Ni-19Al-3Pt is shown in Figure 4b while the partitioning data is listed in Table II. The values for relative site partitioning, $f_{x i}$, (that is, relative to the overall PGM concentration in $\gamma^{\prime}$ ) were given by a statistical ALCHEMI program based on matching of the X-ray maps [13]. This was converted to preference ratios, $k_{N i / A l}$, by taking into consideration the $1: 3$ ratio of $\mathrm{Al}$ sites to $\mathrm{Ni}$ sites through the normalisation equation

$$
k_{N i / A l}=\frac{f_{P G M, N i}}{3 \cdot f_{P G M, A l}}
$$

In the case of Ni-19Al-3Ru several scans were taken using different precipitates, orientations and scanning conditions. In all cases the site distribution ratios were found to be reasonably similar, which was indicative of the reproducible nature of the data. As such, only two scans were performed for each of the other alloys (except Ni-19Al-3Pt where only one was done). The results shown in Table II refer to the partitioning data for the more 
$\mathrm{Al}(\mathrm{K})$

(a)

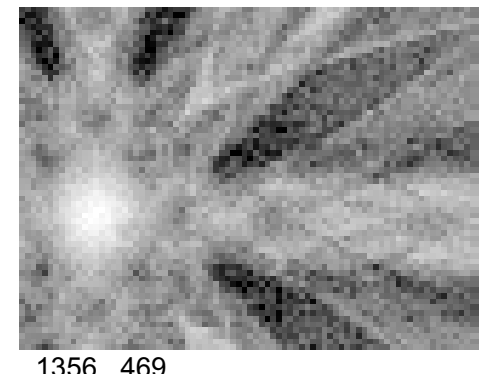

$1356 \quad 469$
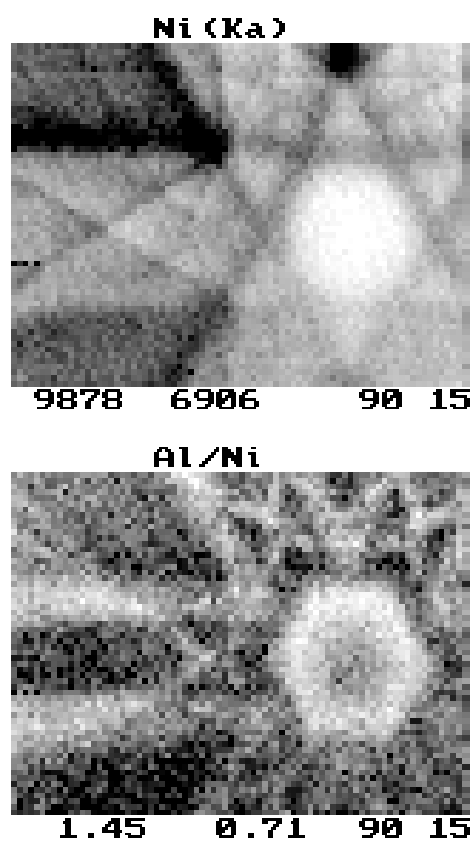

(b)
$\mathrm{Ni}(\mathrm{Ka})$

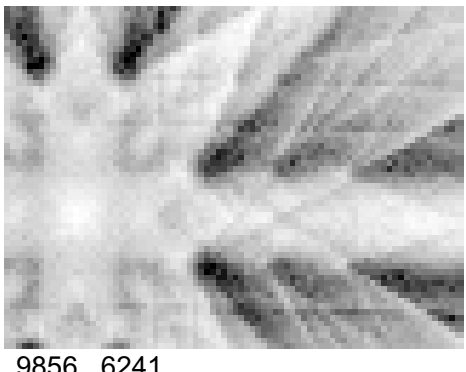

$\overline{9856} \quad \overline{6241}$

Al (K)

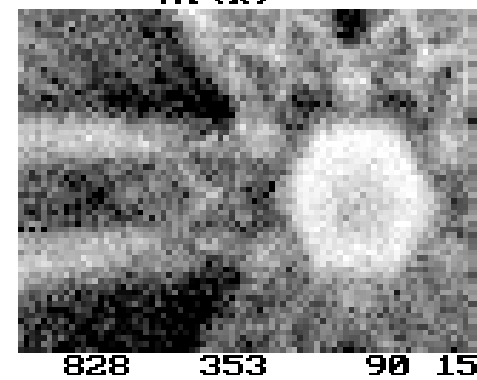

$\mathbf{P t} / \mathbf{N i}$

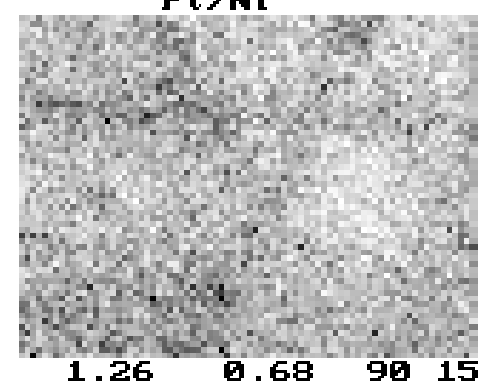

$\mathrm{Al} / \mathrm{Ni}$

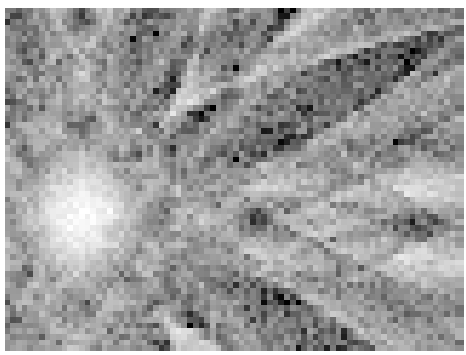

$1.58 \quad 0.73$

Figure 4: Rocking beam X-ray channelling patterns (a) for $\gamma^{\prime}$ in Ni-19.5Al, <100> zone, and (b) for $\gamma^{\prime}$ in Ni-19Al-3Pt, $<111>$ zone.

accurate analyses (although there tended to be little difference in the numerical values obtained). The $\chi^{2}{ }_{\mathrm{R}}$ value is a fit parameter indicating how closely the model inherent in the ALCHEMI statistical analysis fits the actual data. The closer the value gets to unity the better the fit.

The data shows that, of the PGMs, Ru has a preference for the Al sites while $\mathrm{Rh}, \mathrm{Pd}$, Ir and $\mathrm{Pt}$ all have a preference for the $\mathrm{Ni}$ sites in $\mathrm{Ni}_{3} \mathrm{Al}$. Combining these quantitative results with observations made in the C17-based alloys should be done with due consideration of the fact that the atomic site distribution ratios relate specifically to $\mathrm{Ni}_{3} \mathrm{Al}$, which does not necessarily behave identically to highly alloyed $\gamma$ '. The analyses presented in this study are likely to be indicative of the behaviour in complex $\gamma$, but cannot be definitively used to predict how the PGMs partition in $\gamma^{\prime}$ precipitates of advanced multicomponent superalloys. For

Table II. Site partitioning of the PGMs in $\mathrm{Ni}_{3} \mathrm{Al}$ determined using statistical ALCHEMI.

(Note that all experiments were carried out at room temperature).

\begin{tabular}{|c|c|c|c|c|c|c|c|c|c|c|c|c|}
\hline \multirow{2}{*}{ Alloy } & \multirow{2}{*}{ Zone } & \multicolumn{3}{|c|}{$\gamma^{\prime} \operatorname{comp}($ at $\%)$} & \multirow{2}{*}{ Pixels } & \multirow{2}{*}{$\begin{array}{c}\text { Average } \\
\text { cps }\end{array}$} & \multicolumn{3}{|c|}{ Relative partitioning (\%) } & \multicolumn{2}{|c|}{ Ni preference ratio } & \multirow{2}{*}{$\begin{array}{l}\text { X-ray } \\
\text { line, } \\
\text { PGM }\end{array}$} \\
\hline & & $\mathbf{N i}$ & Al & PGM & & & $\mathbf{N i}$ & error $(+/-)$ & $\chi_{\mathrm{R}}^{2}$ & $\mathbf{k}_{\mathrm{N} \mathbf{i} / \mathbf{A l}}$ & error $(+/-)$ & \\
\hline Ni-19Al-3Ta & $<111>$ & 75.0 & 21.0 & 4.0 & $80 \times 60$ & 21,300 & 7.3 & 1.3 & 1.03 & 0.03 & 0.01 & $M$ \\
\hline \multirow{3}{*}{$\mathrm{Ni}-19 \mathrm{Al}-3 \mathrm{Ru}$} & $<100>$ & 74.0 & 24.0 & 2.0 & $40 \times 29$ & 55,000 & 36.9 & 1.1 & 1.01 & 0.20 & 0.01 & $\mathrm{~L}$ \\
\hline & $<111>$ & 74.0 & 24.0 & 2.0 & $80 \times 60$ & 13,500 & 44.4 & 1.6 & 0.98 & 0.27 & 0.02 & $\mathrm{~L}$ \\
\hline & $<111>$ & 75.0 & 23.0 & 2.0 & $80 \times 60$ & 22,000 & 42.4 & 1.4 & 1.01 & 0.25 & 0.01 & $\mathrm{~L}$ \\
\hline $\mathrm{Ni}-19 \mathrm{Al}-3 \mathrm{Rh}$ & $<111>$ & 73.5 & 24.5 & 2.0 & $80 \times 60$ & 21,200 & 84.0 & 1.7 & 1.04 & 1.76 & 0.22 & $\mathrm{~L}$ \\
\hline $\mathrm{Ni}-19 \mathrm{Al}-3 \mathrm{Pd}$ & $<111>$ & 71.0 & 25.0 & 4.0 & $80 \times 60$ & 15,800 & 95.7 & 1.2 & 1.03 & 7.35 & 2.16 & $\mathrm{~K} \alpha$ \\
\hline Ni-19Al-3Ir & $<111>$ & 74.5 & 22.0 & 3.5 & $80 \times 60$ & 15,400 & 77.7 & 0.9 & 1.11 & 1.16 & 0.06 & $\mathrm{~L} \alpha$ \\
\hline Ni-19Al-3Pt & $<111>$ & 72.0 & 21.0 & 7.0 & $80 \times 60$ & 19,600 & 80.4 & 0.7 & 1.21 & 1.36 & 0.06 & $\mathrm{~L} \alpha$ \\
\hline
\end{tabular}


example, competitive partitioning may be applicable to atomic site occupancies in a similar fashion to that proposed for $\gamma / \gamma$, phase partitioning (see below).

\section{Discussion}

\section{$\underline{\gamma / \gamma^{\prime}}$ Partitioning Ratios}

It would appear that all the PGMs give rise to some attenuation in the degree of partitioning of $\mathrm{C} 17$-specific elements, i.e. as the PGMs are added to $\mathrm{C} 17$ one or more of the elements $\mathrm{Ni}, \mathrm{Co}, \mathrm{Ta}$, $\mathrm{W}, \mathrm{Re}$ and $\mathrm{Al}$ show reduced phase preference. In general the most strongly partitioning elements, $\mathrm{Re}, \mathrm{Co}, \mathrm{Al}$ and $\mathrm{Ta}$ show the greatest effects. This phenomena has been observed elsewhere by O'Hara et al. [4], who termed this behaviour "reverse partitioning". Although the compositions of the alloys they used were slightly different, $\mathrm{Ru}$ was an alloying species which was found to promote this change.

The effects of "reverse partitioning" may potentially be utilized to enhance the high temperature structural properties of these critical materials. Very few researchers have investigated this thoroughly but it is possible to make some inferences by considering the data collected in this study. The main point to note is that the volume fraction of $\gamma^{\prime}$ appeared to be different between the alloys and there may be some correlation between this physical property and the observed changes in partitioning ratio.

Re shows very strong $\gamma$-partitioning characteristics. Across all the C17-based alloys it consistently displays the greatest partitioning effect, being almost exclusively located in the matrix. The attenuating effect of the PGMs on this has some important implications: since $\operatorname{Re}$ has a relatively large atomic radius the lattice misfit would be expected to become more positive, as a decrease in the lattice parameter of $\gamma$ would be expected. It is interesting to note that the effect of the PGMs on Re seems to be opposite to that of $\mathrm{Cr}$. It has been argued that at a microstructural level a major benefit of incorporating $\mathrm{Cr}$ in Ni-base superalloys is its ability to increase Re partitioning to $\gamma$ [14], which produces a more negative lattice mismatch between the coherent precipitates and matrix, reduces particle growth rates and induces rafting during high temperature creep deformation. The beneficial effects of Re on creep deformation have been documented [15] and $\mathrm{Cr}$ additions have been attributed to the increase in $\mathrm{Re}$ levels measured in the $\gamma$ phase. For many advanced single crystal alloys which contain significantly higher levels of $\operatorname{Re}(\sim 6 \mathrm{wt} \%$ compared to $\sim 3 \mathrm{wt} \%$ ), supersaturation of $\mathrm{Cr}$ and $\mathrm{Re}$ occurs in the $\gamma$ phase leading to the precipitation of deleterious topologically-closepacked (TCP) phases.

Addition of PGMs, most notably Ru and Ir, seem to mitigate this behavior and cause the alloys to be more resistant to phase instabilities at elevated temperature.

Effects associated with the PGM additions may potentially be attributed to competitive partitioning [16] of the various alloying elements. The basic idea behind this is that in a multi-component system there is a competition between constituent elements to occupy the available phases. The resulting partitioning behaviour is a balance between intrinsic partitioning tendency and the competitive order in which this occurs. Hence it may be concluded that the stronger $\gamma$-partitioning elements $\mathrm{Re}$ and $\mathrm{Co}$ preferentially "filled" the $\gamma$ phase at the expense of $\mathrm{Ru}$. Consistent with these arguments is the observation that a smaller degree of $\mathrm{Ru}$ partitioning was measured in the multicomponent $\mathrm{C} 17+3 \mathrm{Ru}$ alloy when compared to the Ni-19Al-3Ru alloy, Table IIIi. It is interesting to note that the reverse partitioning effect of $\mathrm{Ru}$ can also be observed between the binary Ni-19.5Al and ternary Ni19Al-3Ru alloys (see Al partitioning results in Table IIIii). These results are consistent with the microstructural observations [17] and indicate that significant thermodynamic changes occur as a result of these PGM additions.

Table IIIi: $\gamma / \gamma^{\prime}$ phase partitioning in the ternary Ni-Al-PGM alloys. (a) PGM partitioning in the ternary Ni-19Al-3PGM alloys as compared with their C17-based alloy counterparts.

\begin{tabular}{|c|c|c|}
\hline PGM & Ni-19Al-3PGM & C17+3PGM \\
\hline $\mathrm{Ru}$ & 1.8 & 1.3 \\
\hline $\mathrm{Rh}$ & 0.9 & 0.7 \\
\hline $\mathrm{Pd}$ & 0.5 & 0.5 \\
\hline $\mathrm{Ir}$ & 1.1 & 0.8 \\
\hline $\mathrm{Pt}$ & 0.5 & 0.5 \\
\hline
\end{tabular}

Table IIIii: Al partitioning in the ternary Ni-19Al-3PGM alloys.

\begin{tabular}{|c|c|}
\hline Alloy & $\boldsymbol{k}_{\gamma / \boldsymbol{\gamma}^{\mathbf{j}}}$ Al \\
\hline Ni-19.5Al & 0.60 \\
\hline Ni-19Al-3Ru & 0.75 \\
\hline Ni-19Al-3Rh & 0.65 \\
\hline Ni-19Al-3Pd & 0.55 \\
\hline Ni-19Al-3Ir & 0.70 \\
\hline Ni-19Al-3Pt & 0.80 \\
\hline
\end{tabular}

Comparing the partitioning data with other studies gives reasonably good agreement. Investigations by Murakami et al [18], Tatlock and Hurd [19] and Yokokawa et al. [11] show similar results to those presented despite the use of differing analysis technique (EDS, APFIM and EPMA). Their studies showed comparable PGM partitioning characteristics and evidence of induced attenuation of phase preference for other elements in the alloys used. However, their results do contradict the way in which Ru and Ir affect partitioning of Re and Ta as shown in this study. A possible explanation for this may be attributed to the differences in alloy compositions investigated.

Application of Statistical ALCHEMI to $\gamma$ ' Precipitates in Ni-Al-X $\underline{\text { Alloys }}$

The partitioning of Ru was very strong although not as strong as that of Ta. Jia [20] showed that when a ternary element tends to substitute for the $\mathrm{Al}$ site in $\mathrm{Ni}_{3} \mathrm{Al}$ it stabilises $\gamma^{\prime}$ whereas $\mathrm{Ni}$ site substitution gives rise to $\gamma$ stabilisation. $\mathrm{Ru}$ appears to preferentially occupy $\mathrm{Al}$ sites, but the addition of $\mathrm{Ru}$ to $\mathrm{C} 17$ leads to enhanced $\gamma$ formation [17]. These two seemingly contradictory properties can be reconciled by appealing to the phenomena of reverse phase partitioning induced by Ru. It can be argued that in changing the partitioning characteristics of other constituent elements within the $\gamma+\gamma^{\prime}$ alloy, Ru can lower $\gamma^{\prime}$ content while occupying $\mathrm{Al}$ sites within this phase. Ru should be thought of as a $\gamma$ former but the mechanisms leading to this are different from the conventional $\gamma$ formers such as $\mathrm{Ni}$ and Co. In many ways it can also be considered in a similar light to Re in that it is a HCP metal which preferentially partitions to $\gamma$ in superalloys, yet shows a strong tendency to occupy Al sites when present in $\gamma$ '. 
While $\mathrm{Ru}$ was found to preferentially occupy $\mathrm{Al}$ sites, the other PGMs were found to preferentially partition to $\mathrm{Ni}$ sites in $\mathrm{Ni}_{3} \mathrm{Al}$ in the order $\mathrm{Pd}>\mathrm{Rh}>\mathrm{Pt}>\mathrm{Ir}$. This was consistent with the $\gamma / \gamma$ ' lattice misfit measurements taken from this set of alloys which showed that the PGMs resulted in a significant expansion of the $\gamma$ ' lattice [17]. Taking the Goldschmidt atomic radii (see Table IV), such effects arguably would not have existed if the PGMs had substituted for large $\mathrm{Al}$ atoms.

Table IV. Atomic (Goldschmidt) radii for selected elements.

\begin{tabular}{|c|c|}
\hline & Goldschmidt radius $(\mathbf{\AA})$ \\
\hline $\mathrm{Ni}$ & 1.25 \\
\hline $\mathrm{Al}$ & 1.43 \\
\hline $\mathrm{Ru}$ & 1.34 \\
\hline $\mathrm{Rh}$ & 1.34 \\
\hline $\mathrm{Pd}$ & 1.37 \\
\hline $\mathrm{Ir}$ & 1.35 \\
\hline $\mathrm{Pt}$ & 1.38 \\
\hline $\mathrm{Co}$ & 1.26 \\
\hline $\mathrm{Ta}$ & 1.47 \\
\hline $\mathrm{W}$ & 1.41 \\
\hline $\mathrm{Re}$ & 1.38 \\
\hline
\end{tabular}

Although the atomic site partitioning ratios for Ir showed a very slight preference for the Ni sites, given the magnitude of the errors involved, the results are more indicative of no site preference. Such behaviour has been observed elsewhere with other elements, for example as $\mathrm{Cr}$ and $\mathrm{Fe}[21,22]$, and has been attributed to the similarity in the energetics of the $\mathrm{Ni}-\mathrm{X}$ and $\mathrm{Al}-\mathrm{X}$ interaction, where $\mathrm{X}$ is the substitutional element [23]. This behaviour goes some way to explaining the subtle increase in the positive nature of the $\gamma / \gamma$ ' lattice misfit [17].

In order to develop a more fundamental understanding of the PGM site partitioning in $\mathrm{Ni}_{3} \mathrm{Al}$, the crystallography of the stoichiometric superlattice should be considered. The coordination shell surrounding each of the $\mathrm{Al}$ atoms is completely filled with $12 \mathrm{Ni}$ nearest neighbours; and $\mathrm{Ni}$ atoms are surrounded by $8 \mathrm{Ni}$ and $4 \mathrm{Al}$ nearest neighbours. Qualitatively then, it is clear that if a given ternary addition prefers the formation of a Al-X bond to Ni$\mathrm{X}$ bonds, $\mathrm{X}$ will occupy Ni sites (Type I partitioning). Similarly a dominant $\mathrm{Ni}-\mathrm{X}$ preference would suggest that $\mathrm{X}$ will prefer to occupy the Al sites (Type II partitioning) [24]. Therefore it may be concluded that the Ni-PGM bond is stronger than the Al-PGM bond for $\mathrm{Ru}$, whereas the opposite is true for $\mathrm{Rh}, \mathrm{Pd}$ and Pt. For Ir these bond strengths may be considered as being roughly equal (Type III partitioning). Thus a mechanism can be proposed for the correlation between site preference in $\mathrm{Ni}_{3} \mathrm{Al}$ and phase partitioning in $\gamma / \gamma$. In general it can be seen that the $\gamma$-partitioning $\mathrm{Ru}$ preferentially substitutes for Al and the $\gamma^{\prime}$-partitioning PGMs occupy $\mathrm{Ni}$ sites, which can be understood in terms of the thermodynamic driving force of the system to form the strongest bonds. This argument is based on the underlying principles behind theoretically determined site substitution in $\mathrm{Ni}_{3} \mathrm{Al}$, that is, nearest neighbour electron pair interactions (NN EPI). However, atomic size effects must also play a role and should be considered in combination with electronic interactions. For example, Ir should preferentially occupy $\mathrm{Al}$ sites given that it partitions to $\gamma$ in Ni19Al-3Ir, but its deviation from this could be due to the size differential between the $\mathrm{Al}$ vacancy and diameter of the Ir atom.
Comparison of the results with the limited literature available gives reasonable agreement. A full empirical approach to PGM atomic site partitioning in $\mathrm{Ni}_{3} \mathrm{Al}$ has not been done before, but through modelling Jia [20] has investigated this area. His results indicated that all the PGMs partition preferentially to $\mathrm{Ni}$ sites. Hence the behaviour of $\mathrm{Ru}$ becomes contentious. It is believed that Jia's data may be subject to some errors due to the simplifications made during modelling, in order to minimise calculation times.

\section{Conclusions}

At a microstructural level the PGMs Ru, Rh, Pd, Ir and Pt have differing effects. $\gamma / \gamma^{\prime}$ phase partitioning data indicated that the PGMs alter the partitioning behavior of the constituent elements to different degrees, with $\mathrm{Ru}$ displaying the greatest influence. In accordance with other studies it was found that $\mathrm{Ru}$ partitions to the $\gamma$ phase in a $6 w t \% R e$ alloy while $\mathrm{Rh}, \mathrm{Pd}, \mathrm{Ir}$ and $\mathrm{Pt}$ partition to $\gamma$. The low solubility of $\mathrm{Rh}$ and $\mathrm{Pd}$ in the alloys should also be considered.

Atomic site partitioning of the PGMs in $\mathrm{Ni}_{3} \mathrm{Al}$ showed that $\mathrm{Ru}$ has a strong preference for $\mathrm{Al}$ sites while $\mathrm{Pd}, \mathrm{Rh}$ and Pt preferentially go to Ni sites. Ir showed no significant bias to either site. This implies there is a correlation between $\gamma / \gamma^{\prime}$ phase partitioning and atomic site partitioning; and Ni-PGM/Al-PGM bond strengths offer a likely explanation.

\section{Acknowledgements}

The authors would like to thank Dr C.J. Rossouw for his assistance in application of the ALCHEMI technique. Also RollsRoyce and the Platinum Development Initiative of South Africa for their contribution of materials.

\section{References}

1. M.J. Goulette, "The future costs less - High Temperature Materials from an Aeroengine Perspective," Proceedings of Eighth International Symposium on Superalloys (Superalloys 1996), Seven Springs, Pennsylvania, The Minerals, Metals and Materials Society, USA, 3-6.

2. T. Kobayashi, Y. Koizumi, T. Yokokawa, S. Nakazawa and H. Hiroshi, "The Effect of Platinum Group Metals on the Creep Behaviour of a Third Generation Single Crystal Superalloy," Proceedings of JIM Spring Meeting 2000.

3. T. Kobayashi, Y. Koizumi, T. Yokokawa and H. Harada, "Development of a 4th Generation DS Superalloy," Journal of the Japan Institute of Metals, 66(9) (2002), 897-900.

4. K.S. O'Hara, W.S. Walston, E.W. Ross and R. Darolia, "Nickel Base Superalloy and Article" (Patent No. US5482789, General Electric Co., USA, 1996).

5. D.R. Coupland, C.W. Corti and G.L. Selman, "The PGM [Platinum Group Metals] concept: Enhanced Corrosion Resistant Superalloys for Industrial and Aerospace Applications," Proceedings of Behaviour of High Temperature Alloys in Aggressive Environments, Petten, The Netherlands, 1979, 525536. 
6. D.R. Coupland, C.W. Hall and I.R. McGill, "PlatinumEnriched Superalloys. A Development Alloy for use in Industrial and Marine Gas Turbine Environments," Platinum Metals Review, 26(4) (1982), 146-157.

7. G.J. Tatlock and T.J. Hurd, "Platinum and the Oxidation Behavior of a Nickel Based Superalloy," Oxidation of Metals, 22(5-6) (1984), 201-226.

8. G.J. Tatlock, T.J. Hurd and J.S. Punni, "High Temperature Degradation of Nickel Based Alloys," Platinum Metals Review, 31(1) (1987), 26-31.

9. G.J. Tatlock and T.J. Hurd, "Platinum and the Hot Corrosion Behaviour of a Nickel Based Superalloy," Werkstoffe und Korrosion (Germany), 41(12) (1990), 710-715.

10. H. Murakami., private communication with author, Japan National Institute for Materials Science, November 2000.

11. T. Yokokawa, M. Osawa, K. Nishida, T. Kobayashi, Y. Koizumi and H. Harada, "Partitioning Behavior of Platinum Group Metals on the Gamma and Gamma' Phases of Ni-Base Superalloys at High Temperatures," Scripta Materialia, 49(10) (2003), 1041-1046.

12. A.P. Ofori, C.J. Rossouw and C.J. Humphreys, "Using ALCHEMI to Determine the Site Occupancy of $\mathrm{Ru}$ in the $\mathrm{L}_{2}$ Phase of a Ni-Base Superalloy," (Paper submitted to Acta Materialia (USA) for publication, 2004).

13. C.J.R. Rossouw, computer program: "Statistical ALCHEMI," Melbourne, Australia, 1980.

14. J. Smith, "Effects of Chromium and Rhenium Additions Upon Coarsening and Deformation Behavior of Single-Crystal Nickel-Base Model Superalloys," (Ph.D. thesis, University of Illinois, USA, 1988).

15. A.F. Giamei and D.L. Anton, "Rhenium Additions to a Nickel-Base Superalloy: Effects on Microstructure," Metallurgical Transactions A, 16A(11) (1985), 1997-2005.

16. H. Murakami, T. Honma, T. Yokokawa, Y. Koizumi and H. Harada, "The Distribution of Iridium in Ni-Base SingleCrystal Superalloys," Proceedings of International Symposium on Iridium, Tennessee, 2000, The Minerals, Metals \& Materials Society, USA, 121-128.

17. A.P. Ofori, "Effects of PGM Additions to an Advanced Single Crystal Nickel-Base Superalloy," (Ph.D. thesis, University of Cambridge, UK, 2003).

18. H. Murakami, T. Honma, Y. Koizumi and H. Harada, "Distribution of Platinum Group Metals in Ni-Base Single-Crystal Superalloys," Proceedings of Ninth International Symposium on Superalloys (Superalloys 2000), Seven Springs, Pennsylvania, The Minerals, Metals and Materials Society, USA, 747-756.

19. G.J. Tatlock and T.J. Hurd, "An EDS Investigation of the Oxidation of Superalloys," Proceedings of Electron Microscopy 1982, Hamburg, West Germany, Deutsche Gesellschaft fur Elektronenmikroskopie, West Germany, 691-692.
20. C.C. Jia, (PhD thesis, Tohoku University, Japan, 1990).

21. S. Ochiai, Y. Oya and T. Suzuki, "Solubility Data in $\mathrm{Ni}_{3} \mathrm{Al}$ with Ternary Additions," Bulletin of the Research Laboratory for Precision Machinery Electronics, 52 (1983), 1-17.

22. D. Shindo, M. Kikuchi, M. Hirabayashi, S. Hanada and O. Izumi, "Site Determination of Iron, Cobalt and Chromium Atoms added in $\mathrm{Ni}_{3} \mathrm{Al}$ by Electron Channelling Enhanced Microanalysis," Transactions of the Institute of Metals (Japan), 29(12) (1988), 956-961.

23. M. Enomoto and H. Harada, "Analysis of Gamma/Gamma Equilibrium in Ni-Al-X Alloys by the Cluster Variation Method with the Lennard-Jones Potential," Metallurgical Transactions A, 20A(4) (1989), 649-664.

24. C. Wolverton and D.D. Fontaine, "Site Substitution of Ternary Additions to $\mathrm{Ni}_{3} \mathrm{Al}$ (Gamma') from Electronic-Structure Calculations," Physical Review B: Condensed Matter (USA), 49(17) (1984), 12351-12354. 